\title{
Chronic inflammation, C-reactive protein, and breast health: future directions to predict, prevent, personalize and inspire consumerism in the mitigation of breast cancer
}

\author{
CY Covington*1, D Lithgow ${ }^{2}$, R Zangar ${ }^{3}$, MS Abdullah ${ }^{4}$ and R Jimenez ${ }^{5}$
}

\author{
Address: ${ }^{1}$ Texas Tech University Health Sciences Center, Lubbock, TX, USA, ${ }^{2}$ Western University of Health Sciences, Pomona, CA, USA, ${ }^{3}$ Biological \\ Sciences Division, Pacific Northwest National Laboratory, Richland, WA, USA, ${ }^{4}$ Aga Khan Medical Center, Nairobi, Kenya and ${ }^{5}$ Department of \\ Dairy Science, California Polytechnic State University, San Luis Obispo, CA, USA \\ Email: CY Covington* - chandice.covington@ttuhsc.edu \\ * Corresponding author
}

from 6th International Symposium on the Intraductal Approach to Breast Cancer

Santa Monica, CA, USA. I9-2I February 2009

Published: 24 July 2009

BMC Proceedings 2009, 3(Suppl 5):S2 doi:10.1186/1753-656I-3-S5-S2

This abstract is available from: http://www.biomedcentral.com/1753-656I/3/S5/S2

(C) 2009 Covington et al; licensee BioMed Central Ltd.

Breast cancer incidence has dropped dramatically with further reductions predictably linked to lifestyle/behavioral and environmental changes. About $98 \%$ of malignant breast conditions emanate within the epithelial cell compartment in the breast ductal system. Premalignant cell damage in this lining signals a biochemical cascade that deliver inflammatory proteins to the site. One protein, $\mathrm{CRP}$, is associated with carcinogenic risk. An inflammation cell milieu amendable to efficient, low cost, preventive interventions that impede biochemical/molecular conversion to cancer would offer a 'disruptive innovation' with public health implications. Nipple aspirate (NAF), a non-invasively obtained tissue sample, is a rich source of protein markers manufactured by the ductal system. First, Lithgow's dissertation determined if CRP relates to reproductive, nutrition, and body composition and activity factors. Results were that age at first pregnancy, gravidity, wean time from breast-feeding last baby, \%fat, and BMI, with $\mathrm{p}<.05$, and serum triglycerides $(\mathrm{p}=.01)$, were related significantly to CRP levels in NAF. A model derived from selective factors significantly $(p=.05)$ accounted for the variance in CRP in NAF. Second, Lithgow evaluated if risk factors, as identified by the Gail model, were associated with NAF CRP levels. CRP in NAF significantly $(\mathrm{p}=.04)$ and positively related to breast cancer risk as predicted by the Gail model. A third bio-cultural study offers a perspective breast microenvironment that challenges western views of the female breast. Proteins prevalent in grandmother age $(35-70$ years of age)breast fluids collected in an investigation of the use of re-lactation in response to a goal to reduce infant exposure to HIV transferred in mother's breast milk found that these grandmothers could re-establish a nutritious/adequate milk supply equivalent with the cell and protein components of human milk. The inflammatory hypothesis, as a potential preventive base to support breast-feeding support for maternal health, systematic testing of NAF, serial expression of NAF, dietary supplements and other innovations taken together promise further reductions of breast cancer incidence. The western view of female breast pathophysiology may benefit from a 'disruptive innovation' philosophy applied to the translational model of knowledge development that is predictive, preventive, personalized, and participatory in the mitigation of breast cancer. 